\title{
Organizational Commitment in the Nonprofit Sector and the Underlying Impact of Stakeholders and Organizational Support
}

\author{
Rong Wang ${ }^{1}$ (D)
}

Accepted: 9 February 2021 / Published online: 3 March 2021

(C) International Society for Third-Sector Research 2021

\begin{abstract}
This study addresses a major challenge the nonprofit sector is facing: low organizational commitment from employees. In response to the call to take into consideration contextual and institutional factors, it draws from the stakeholder theory and the organizational support theory to investigate how internal and external organizational processes could influence organizational commitment. The quantitative data collected from over 200 nonprofit employees revealed that organizational commitment was positively related to engaged leadership, community engagement effort, degree of formalization in daily operations, and perceived intangible support for employees. Further analysis showed that tangible support measured as perceived fair pay has an indirect effect, which is contingent upon how well the nonprofits engage with internal and external stakeholders. Findings suggest that nonprofit employees' personal tangible gains may come second when assessing their commitment to the organization; instead, how well their employer manages stakeholder relationships in a larger community plays a more significant role.
\end{abstract}

Keywords Stakeholder engagement · Organizational support · Nonprofit · Organizational commitment

Rong Wang

rong.wang@uky.edu

1 Department of Communication, College of Communication and Information, University of Kentucky, 234 Blazer Dining, 343 S. Martin Luther King Blvd, Lexington, KY 40526, USA

\section{Introduction}

Results from the Johns Hopkins Center for Civil Society's 2019 Nonprofit Employment Report show that the nonprofit sector is the third largest workforce in the USA, employing 12.3 million paid workers in 2016 which accounts for $10.2 \%$ of the total US private workforce (Salamon et al., 2019). Between 2007 and 2016, the rate of job growth in the nonprofit sector outpaced the for-profit sector by over 3 to 1 , including during recessionary periods. Employees in the nonprofit sector are often attracted to the job through their identification with an organization's social and humane mission (Bassous, 2015), hoping to provide meaningful value for a society.

Despite the fact that the nonprofit industry is a promising field for job creation and growth, the sector faces major challenges. Smith et al. (2006) pointed out that employees in the nonprofit sector tended to be overworked, yet underpaid. Recent research also reported that the nonprofit sector had a high turnover rate and lower employee satisfaction than other sectors (Lee, 2016). These issues are related to employee engagement, which has been a highly studied area in both the private sector and the public sector. The research on employment engagement in the nonprofit sector, however, is lacking. This study focuses on understanding one specific aspect of employment engagement: employee's organizational commitment (Akingbola \& van den Berg, 2019; Knapp et al., 2017). Understanding this issue could offer managerial and communication implications to enhance nonprofit workforce stability and organizational performance (Kang, 2015; Lee and Nowell, 2015).

This study draws from two theoretical frameworks, the stakeholder theory and organizational support theory, to examine this overarching question: How do internal and external factors influence nonprofit employees' 
organizational commitment? The stakeholder theory informs the study by identifying diverse social groups nonprofits should be accountable for in order to maintain workforce stability. The organizational support theory conceptualizes the relational aspects of organizational life and thus offers explanations regarding what tangible and intangible resources may function as incentives to influence organizational commitment. Guided by these two theories, this study focuses on the effects of the following factors: stakeholder engagement, engaged leadership, degree of formalization in operation, and organizational support.

This research makes several contributions to nonprofit studies. First, it provides a new angle in analyzing nonprofit commitment by accounting for influences from external and internal stakeholders. Second, it moves beyond traditional communication issues the nonprofit sector faces in ensuring workplace stability, and focuses on how to address needs related to employees' expectations and community relationships.

\section{Organizational Commitment in the Nonprofit Sector}

Employment is essentially a social exchange relationship where employees help the organization achieve its goals and objectives while at the same time the organization provides a supportive environment to fulfill the employees' needs for self-enhancement, belonging, and other socioemotional needs (Kurtessis et al., 2017). Organizational commitment refers to the levels of attachment employees felt toward their organization (Bartlett, 2001). It has been conceptualized as attitudinal and behavioral components of this relationship from the employee's perspective, which entails a relatively stable measurement of employee attribute regarding their belief in the organization's goal, willingness to invest in the organization, and desire to maintain the organizational membership (Angle \& Perry, 1981; Porter et al., 1974). Organizations with committed employees could avoid high turnover rates and experience higher productivity.

Employee's organizational commitment is fundamentally a concept in studying employee engagement, which has generated a lot of interest in different sectors, particularly in the private and public sectors (Angle \& Perry, 1981; Yousef, 2017). Kang et al. (2015) pointed out that the literature on organizational commitment originated from the human resource perspective which focused on psychological factors such as burnout issues and motivations and then moved toward organizational management and business management perspectives which analyzed cost-benefits of organizational exit. Three sets of organizational factors have been examined to uncover what affects organizational commitment: personal demographic attributes (such as personality and gender), job-related attributes (e.g., task organization), and job perception (e.g., job satisfaction).

However, there is a lack of consensus about how these factors may influence employee's organizational commitment (Akingbola \& van den Berg, 2019). One possible reason is that organizational commitment has been defined in various ways, resulting in a lack of consistency in the measurement and effect interpretation (Yahaya \& Ebrahim, 2016). For example, some research measures organizational commitment as an antecedent of job satisfaction and other organizational outcomes (Huynh et al., 2012; Powell \& Meyer, 2004); while some other studies conceptualize it as an outcome affected by organizational factors (Presti, 2013; Salim et al., 2012).

This study follows the three-component model of organizational commitment proposed by Meyer et al. (1993), which has shown its ability to predict employees' behavioral intentions in empirical research (Valeau et al., 2016). Meyer et al. (1993) differentiated between affective, normative, and continuance commitment. These components are discussed in detail below. To begin with, affective commitment captures employees' identification and emotional attachment to the organization, based on shared values and goals. This component is the most frequently examined dimension of organizational commitment (Huynh et al., 2012). Existing studies have drawn from the organizational identification literature to emphasize the importance of affective commitment in influencing employees' intention to stay in an organization. Individuals with high affective commitments strongly identify with the organization and will be more committed to pursue its goals (Darolia et al. 2010). In nonprofits, individuals with high affective commitment are more likely to perceive strong organizational pride and view themselves as being respected and valued, leading to a stronger commitment to organizational values and social missions (Boezeman \& Ellemers, 2007).

The second dimension is the normative commitment, which focuses on employees' feeling of obligation to stay with an organization because of personal values. It captures the moral duty and indebted obligations (Meyer \& Parfyonova, 2010). Employees with high normative commitment believe that the organization expects them to be loyal (Allen \& Meyer, 1990). In nonprofits, normative commitment has been captured by employees' willingness to act upon their obligation and advocate for the organization (Valeau et al. 2016). Advocacy actions include fighting for organizations' social mission or refer a friend or a family member to work at the organization. 
Lastly, the continuance commitment captures employees' desire to remain in an organization due to the awareness of the cost related to departure. It involves the use of reasoning to determine whether the benefits of staying as an organizational member would surpass the cost. Nonprofit employees often face a high level of stress and burnout (Lee, 2016). Employees may evaluate their pay and other job-related benefits by taking into account the possible losses and benefits in cases of moving to another organization. The existing literature has looked into how work-life balance may affect the continuance commitment, which is measured as turnover intention (Yahaya \& Ebrahim, 2016).

To summarize, this study applies the three-component conceptualization of organizational commitment to the context of nonprofit organizations to highlight the following dimensions: pride (affective), advocacy (normative), and turnover intention (continuance). This multidimensional conceptualization examines a more comprehensive picture of nonprofit employees' attachment to their organization (Truss et al., 2013).

Employees often are drawn to nonprofit jobs by social missions (Kim \& Lee, 2007). Nonprofits are expected to address certain social needs to overcome government or market failure (van Puyvelde \& Brown, 2012). Working at a nonprofit involves not only daily business operations but also engaging with "the community-at-large," i.e., the surrounding community the organization serves to fulfill its mission (Zollo et al., 2019). Therefore, it is logical to move beyond the relationship between the employees and the organizations and to analyze a larger context of what internal and external factors might influence their organizational commitment.

\section{Stakeholder Theory and Organizational Commitment}

The stakeholder theory emphasizes that managers need to satisfy the demands of all appropriate stakeholders, defined as groups or individuals that can affect or be affected by an organization's objectives (Freeman, 1984). Stakeholders for nonprofits are "any person or group that is able to make a claim on an organization's attention, resources or output or who may be affected by the organization" (Lewis, 2005, p. 202). Nonprofits are essentially economic entities that internalize the expectations of their stakeholders in defining and developing strategies.

Stakeholders are defined by what is at stake. For example, stakeholders have been defined by whether they come from the demand side (e.g., individuals or groups who pay for a service such as nursing home resources) or the supply side (e.g., sponsors that provide resources for the provision and delivery of services and product) (BenNer \& Van Hoomissen, 1991). Furthermore, stakeholders can be categorized by their power, legitimacy, and urgency (Valeau et al., 2016).

Guided by Lewis's (2005) argument that nonprofits are socially constructed by the communication between external and internal stakeholders to sustain organizational functions, this study adopts the dichotomy defined by the organizational boundary. Internal stakeholders for nonprofits include employees, managers, board members, and volunteers; external stakeholders include funders, beneficiaries, contractors, regulators, community partners, and media (Puyvelde et al., 2012). It argues that how nonprofits manage their relationships with both external and internal stakeholders would influence their employees' organizational commitment.

\section{Leadership to Engage Internal Stakeholders}

Internally, leadership is an important factor in influencing stakeholder engagement (Bassous, 2015; Brimhall, 2019). The more engaged the leadership, the more a nonprofit achieves in addressing internal stakeholders' expectations. Engaged leadership creates a participatory work environment where nonprofit employees' voices are heard and can contribute to decision-making processes (Ohana et al., 2013). Engaged leadership helps retain employees who were initially attracted to the job by its mission (Defourny \& Nyssens, 2008). Leadership of a nonprofit can be examined from two aspects: the executive director in the management team and the board of directors (Lewis, 2005; Shumate et al,. 2017).

Boards of directors for nonprofits are expected to perform both legal and fiduciary responsibilities to ensure nonprofits remain true to its mission and are governed effectively (Miller \& Faerman, 2003). Boards of directors are volunteers, and the composition is often diverse. They help form partnerships with other sectors (Lewis, 2005) and ensure the organization's financial health (Hodge et al., 2011). However, board members often experience role ambiguity (Doherty \& Hoye, 2011; Wright \& Millesen, 2008), leading to limited engagement with nonprofit staff members. The relationship between nonprofit board and employees can significantly influence the stability of a nonprofit (Reid and Turbide 2012).

The management leadership within a nonprofit also plays a significant role in influencing internal stakeholder engagement and organizational commitment. Bassous (2015) found that leadership in faith-based nonprofits significantly affects worker motivation. For example, leadership focusing on delegating instead of micromanaging can guide workers to develop self-motivation and actions. Brown and Yoshioka (2003) showed that frustration with 
management is often a key reason for leaving. Knapp et al. (2017) found that nonprofit leaders providing a supportive and autonomous environment significantly affect employees' perception of the organization. Furthermore, supportive leadership could lead to higher organizational commitment (Jaskyte, 2004). These studies suggest that engaged leadership from the executive team might help retain employees. Taken together the importance of the leadership via board members and executive managers in addressing internal stakeholders' expectations, this study proposes that

H1 A more engaged leadership perceived by a nonprofit employee is positively related to their organizational commitment.

\section{Formalized Internal Operations and Organizational Commitment}

Another internal mechanism influencing employee engagement is the degree of formalization. The literature has long debated whether a nonprofit should be more "business like" to be effective. More formally structured nonprofits involve the following distinct processes: defining a clear goal of what they want to achieve, developing an organizational rhetoric, and having an organizational management (Dart, 2004). The most important features that affect internal stakeholders are organizational structures and formalized management processes (Maier et al., 2016). The structural feature focuses on the internal communication to ensure that employees have the information needed to complete their job effectively (Kearns, 2004) and conflicts are managed well (Jaskyte, 2011; Sanders \& McClellan, 2014). The degree of formalized management processes can be captured by how well a nonprofit measures performance to ensure that all the employees are held accountable for their actions and do not rely on the leadership to micromanage everything (Dart, 2004). Furthermore, it captures how well a nonprofit encourages and accepts employee innovation to help fulfill its mission (Jaskyte, 2011).

Though the nonprofit faces an increasing expectation to be structured and operationalized formally, little is known about how it may influence employees' organizational commitment. The literature, however, provides clear evidence that when nonprofits take on formalized organizational processes, it helps to build operational capacity and improve organizational performance (Shumate et al., 2017). The reason is that the formalized operation facilitates the documentation of procedures and improves accountability (Maier et al., 2016), thus addressing internal stakeholders' needs. Ridder and McCandless (2010) argue that the formalized business operation entails the importance of internal stakeholder engagement and could lead to higher organizational commitment in the nonprofit sector. These processes and practices are essentially about the degree of formalization in nonprofits' business operations to maintain professionalism (Maier et al., 2016). Therefore, the following hypothesis is proposed:

H2 A nonprofit's degree of formalization perceived by employees is positively related to their organizational commitment.

\section{External Stakeholder Engagement and Organizational Commitment}

Externally, nonprofits have to meet expectations from stakeholders, among which communities they serve remain one of the most important groups. This study argues that a nonprofit's ability to communicate with and satisfy local communities would influence its employees' organizational commitment. Community engagement involves communicating about organizational goals, building partnerships with local communities, and distributing information about organizational activities (Balser \& McClusky, 2005). The goal is to keep the external stakeholders informed and to generate community impact.

In the nonprofit sector, an organization's mission provides its employees goals to direct their behaviors and defines a vision for the future. Perceived mission alignment helps attract employees rather than retaining them (Brown \& Yoshioka, 2003). Akingbola and van den Berg (2019) define this alignment as value congruence which affects the relationship between employees, their job, and the organization. Kim and Lee (2007) found that mission orientation between nonprofit employees and the organization significantly influences employee retention. These findings suggest that employees expect the nonprofits to stay true to its mission by understanding the root cause of the social issue as a first step, instead of simply focusing on symptoms (Eikenberry, 2009). They would expect the organization to engage in problem solving by communicating with external stakeholders (such as clients served and local communities) and building a robust partnership to effectively tackle root causes (Kania \& Kramer, 2011). Employees' view of how an organization handles these issues affects their perception of mission alignment, which affects their organizational commitment. Therefore,

H3 A nonprofit's community engagement perceived by the employees is positively related to their organizational commitment. 


\section{Organizational Support and Organizational Commitment}

To further unpack what additional factors may influence organizational commitment in the nonprofit sector from the employees' perspective, this study draws arguments from the organizational support theory (OST). OST captures how employees perceive the relational aspect of organizational life. Its main argument is that when employees believe the organization values their contribution and cares about their well-being and professional development, they are more likely to think and act positively, leading to higher organizational commitment (Akingbola \& van den Berg, 2019). Some studies have applied the OST to examine the nonprofit sector. Knapp et al. (2017) found that higher levels of perceived organizational support are related to lower turnover retention. They did not test how organizational support may influence other aspects of organizational commitment, such as job referral intention and organizational pride. Salim et al. (2012) revealed that organizational support was significantly correlated with organizational commitment. They did not test the direct effect organizational support may have on organizational commitment.

Traditionally, OST has focused on support through tangible resources or extrinsic material such as money, financial instruments, and durable goods. The literature has measured organizational support with how employees perceive the fairness of their pay (Knapp et al., 2017). Recent literature in the nonprofit sector starts to examine intangible assets that are important for career success, quality of life, and psychological well-being. Given that the nonprofit sector is often viewed as a sector where employees are underpaid while overworked, the work environment is viewed as stressful. LeRoux and Feeney (2013) argue that nonprofit employees earn significantly less compared to their for-profit counterparts, with limited access to opportunities for promotion. Kim and Lee (2007) argue that nonprofits offering professional development and career advancement training can help attract and retain qualified employees. Another area of concern is whether the organization attends to the employees' psychological well-being such as mental health needs (Baluch, 2017). Therefore,

H4 The tangible organizational support perceived by nonprofit employees is positively related to their organizational commitment.

H5 The intangible organizational support perceived by nonprofit employees is positively related to their organizational commitment.

\section{Method}

\section{Sampling and Data Collection}

Participants of the survey were recruited in March and April 2019 from a city located in the southeastern region of the USA. This location was chosen for the following reasons. First, the profile of nonprofits in this geographically bounded sample is illustrative of a growing diverse sector (Kentucky Nonprofit Network, 2020a). The county had a total of 1964 registered nonprofits as of 2019, ranging from large-scale organizations such as state universities and hospitals, to small associations. Nonprofits in this county offered over 23,000 jobs, consisting about $15 \%$ of the total nonprofit workforce. Second, the population in the county grew $9 \%$ between 2010 and 2019 based on the US Census data, while the unemployment rate decreased from 8.2 to $3.8 \%$ (US Bureau of Labor Statistics, 2020). This indicates there were still fewer jobs available. However, during this period of time the growth in the nonprofit sector outpaced the annual employment in the private sector by $3.6 \%$. Examining what influences organizational commitment could offer insights on whether the nonprofit sector may attract more employees to fight unemployment. Third, the proximity of the research team to the community allowed for a higher-than-typical response rate. The average response rate for organizational commitment studies was around 35\% (Erdurmazl1, 2019; Onana et al. 2013). This convenience sample provides more insights compared to national studies that offer very little nuance of contextual factors or individual case studies that focus extensively on a single organization.

After eliminating organizations with no revenue or assets in 2017 or no contact information, the final sample consisted of 313 nonprofits. Email invitations were sent out to the sampled organizations and 182 of them completed the survey (response rate $=58 \%$ ). A total of 252 completed surveys were received. The demographics reported in the survey showed that $83 \%$ of the respondents were White/ Caucasian and $8 \%$ were African-American. The respondents were primarily female $(74 \%)$, matching with the general trend in the nonprofit sector (Alexander, 2017; Lanfranchi \& Narcy, 2015). Organizations surveyed represented the following issue areas: arts and culture (19\%), human services $(12 \%)$, food agriculture and nutrition $(10 \%)$, education $(9 \%)$, community improvement $(8 \%)$, mental health and crisis intervention (6\%), youth development (6\%), civil rights, social action, and advocacy $(6 \%)$, housing and shelter $(4 \%)$, animal related $(3 \%)$, and everything else $(15 \%)$. The sample demonstrates a diverse range of social issues. 


\section{Measurement}

Organizational Commitment was measured with three items adopted from Meyer et al. (1993). The respondents were asked to answer the following questions on a scale of 1-5 ( $1=$ no, 2 = somewhat no, $3=$ neutral, $4=$ somewhat yes, and $5=$ yes): Are you proud to be associated with the organization? Would you refer a friend or family member to this organization for employment? Do you ever think about leaving the organization because of how your work impacts your life? These three items captured the affective (pride), normative (advocacy), and continuance (turnover) aspects of organizational commitment. These items (the item about turnover intention was reverse coded) were loaded to one single factor $(M=3.97, \mathrm{SD}=1.08$, Cronbach's $\alpha=0.77$ ).

Engaged leadership was measured with four items on a scale of 1 to 5 to capture the level of engagement employees perceived from the board of directors and the executive team. The questions include: Is the board of directors for your nonprofit actively engaged? Does the leadership act on your recommendations? Is the ED or CEO from your organization an effective leader? Do you ever feel micromanaged by your ED/CEO (reverse-coded)? All the four items were loaded to one single factor $(M=3.82, \mathrm{SD}=1.09$, Cronbach's $\alpha=0.77)$.

Organizational Support was measured with two variables to capture support through the tangible and intangible resources. Tangible support was measured as perceived fair pay (with two items about how the respondents feel that the pay is fair for staff in the organization and also themselves $(M=3.05, \mathrm{SD}=1.46$, Cronbach's $\alpha=0.85)$. Intangible support includes three questions about how they feel about the organization's support with their professional development opportunities, career advancement opportunities, and mental health needs $(M=3.13, \mathrm{SD}=1.12$, Cronbach's $\alpha=0.70$ ).

Degree of Formalization was measured with three questions about internal communication, the extent to which all employees at all levels of the organization were held accountable for their actions, and innovation $(M=3.84, \mathrm{SD}=1.06$, Cronbach's $\alpha=0.80)$.

Community Engagement was measured with three items, asking the respondents to evaluate the organization's external communication with the local community and robust community partnerships, and the extent to which the organization understood the root causes of the issue it seeks to address. All the items were also measured on a scale of $1-5(M=4.10, \mathrm{SD}=0.88$, Cronbach's $\alpha=0.76)$.

The following control variables were measured Gender was measured as a categorical variable $(1=$ female, $2=$ male, and $3=$ non-binary or refuse to answer). Age was measured as an ordinal variable, $1=16-35$,
$2=36-50,3=51-65$, and $4=65+$. Organizational tenure was measured as a categorical variable, $1=0-1$ year, $\quad 2=1-5$ years, $\quad 3=5-10$ years, $4=11-20$ years, and $5=20+$ years. Race was measured with three binary variables to capture the following groups: Caucasian or White $(n=208)$, African-American $(n=20)$, and others including people who reported being Latinx or Hispanic, or Native American, or Multiple, and also people who preferred not to answer $(n=24)$. Organizational roles were measured as a categorical variable, with $1=$ board member, $2=$ executive staff, and $3=$ staff member. The type of employment was measured to capture whether employees had a full-time $(n=165)$ or a part-time $(n=98)$ position at a nonprofit. In addition, the scope of work was measured to reflect, $1=$ local neighborhood, $2=$ local city, $3=$ state, $4=$ regional, $5=$ national, and $6=$ other. Worklife balance was measured to capture the degree to which nonprofit employees agreed that there was a balance between their work and life on a scale of 1-5 (1 indicating strongly disagree and 5 indicating strongly agree), $M=3.41$, S.D. $=1.46$.

\section{Results}

All the variables were screened for normality before the analysis. To test the hypotheses, a multiple regression model was run with all the IVs and control variables. The regression model was significant, $F(15,180)=33.06$, $p<0.001$. All the variables explained $71 \%$ of the variance in the DV. The following factors were positively related to nonprofit employees' organizational commitment: engaged leadership $(B=0.21, S E=0.08, p=0.006)$, community engagement $(B=0.13, \mathrm{SE}=0.06, p=0.04)$, and degree of formalization $(B=0.40, \mathrm{SE}=0.07 p<0.001) . \mathrm{H} 1, \mathrm{H} 2$, and $\mathrm{H} 3$ were supported. The effect of intangible support was also significant and positive $(B=0.11, \mathrm{SE}=0.05$, $p=0.03)$, but tangible support had no effect $(B=-0.04$, $\mathrm{SE}=0.04, p=0.19)$. H4 was not supported. H5 was supported. Gender, race, tenure, age, capacity, and organizational scope were not significantly related to the organizational commitment. Two control variables had significant effects: whether an employee was full time $(B=0.22, \mathrm{SE}=0.11, p=0.04)$, and the perceived worklife balance $(B=0.16, \mathrm{SE}=0.04, p<0.001)$. See the model summary in Table 1 .

To further unpack the effect of tangible support, a post hoc analysis was conducted to examine if any of the variables of stakeholder engagement (i.e., engaged leadership, community engagement, and degree of formalization) would mediate the relationship between tangible support and organizational commitment. Following Hayes and Scharkow (2013), each mediation test was conducted 
Table 1 Summary of the regression model

\begin{tabular}{lc}
\hline & Organizational commitment \\
\hline Intercept & $0.22(0.32)$ \\
Gender-Female & $0.09(0.10)$ \\
Gender-Other & $0.53(0.31)$ \\
Tenure & $-0.01(0.05)$ \\
Race-Caucasian & $-0.20(0.18)$ \\
Race-African-American & $-0.04(0.22)$ \\
Age & $0.07(0.06)$ \\
Capacity & $-0.07(0.11)$ \\
Scope & $0.003(0.04)$ \\
Full time & $0.22(0.11)^{*}$ \\
Work-life balance & $0.16(0.04)^{* * *}$ \\
H1 Engaged leadership & $0.21(0.08)^{* *}$ \\
H2 Community engagement & $0.13(0.06)^{*}$ \\
H3 Degree of formalization & $0.40(0.07)^{* * *}$ \\
H4 Tangible support & $0.05(0.04)$ \\
H5 Intangible support & $0.11(0.05)^{*}$ \\
\hline
\end{tabular}

$* p<0.05, * * p<0.01, * * * p<0.001$

by first running two regression models: one to test the effect of IV on the mediator (a), and the other to test the effect of the mediator on the outcome variable (b), while controlling for the IV (thus, indirect effect $=c^{\prime}$ ). See Fig. 1 for the illustration. The joint significance test was used to determine if a mediation effect was present. If the null hypothesis was rejected, we then used the product of coefficients approach with asymmetric 95\% confidence intervals. Using this approach, we calculated the indirect effect as the product of the coefficients for the IV on the mediator (a) and the mediator on the outcome variable (b). We denote the total effect of the IV on the outcome variable as c. The effect size $[(a * b) / \mathrm{SDy}]$ and proportion mediated $[(a * b) / c]$ were calculated. Bootstrapping was also conducted to verify the mediation results.

Mediation analysis revealed that engaged leadership significantly mediated how tangible support influences organizational commitment $\left(c^{\prime}=0.15, p<0.001\right)$, while there was a significant total effect $(0.21, p<0.001)$ but no

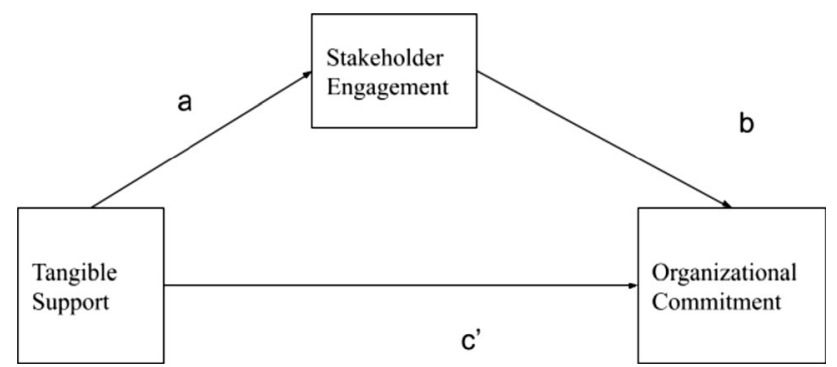

Fig. 1 Mediation role of tangible support insignificant direct effect from tangible support to the outcome variable ( $c=0.06, p=0.10)$. The bootstrapping verified the mediation results and found again a significant mediation effect and the lack of a direct effect. With increased power, the mediation analysis explained $69 \%$ of the total effect.

Similarly, the same mediation effect was found from community engagement $\left(c^{\prime}=0.12, p<0.001\right)$. There was a significant direct effect from tangible support to the outcome variable $(c=0.18, p<0.001)$ and also a significant total effect $(0.30, p<0.001)$. The bootstrapping also verified the mediation results, and the mediation effect explained about $41 \%$ of the total effect.

Furthermore, the degree of formalization also had a significant mediation effect $\left(c^{\prime}=0.16, p<0.001\right)$ while there was a significant total effect $(0.19, p<0.001)$. No significant direct effect was found $(c=0.02, p=0.51)$. The bootstrapping also verified the mediation results, and the mediation effect explained about $87 \%$ of the total effect. See Table 2 for the summarized mediation effects.

All these significant mediation effects indicate that the perceived fair pay as tangible support has a consistent indirect effect on organizational commitment, which is contingent upon how their organization addresses internal and external stakeholders' needs through engaged leadership, community outreach, and formalized business operation.

\section{Discussion}

This study examined what internal and external factors would influence nonprofit employees' organizational commitment, guided by the stakeholder theory and OST. Quantitative data collected from over 200 nonprofit employees revealed that organizational commitment was positively related to engaged leadership, community engagement effort, degree of formalization in nonprofit daily operations, and perceived intangible support. These findings suggest that when assessing their willingness to stay and how they feel about their organization, nonprofit employees think beyond themselves. They place a stronger emphasis on a larger community of stakeholders, including all employees in the organization and local communities their organizations serve. Further analysis showed that tangible support measured as perceived fair pay has an indirect effect on organizational commitment, which is contingent upon how well the nonprofits addressed both internal and external stakeholders through leadership, daily business operation, and community engagement. This further demonstrates that their own personal tangible gains may come second when assessing their commitment to the organization; instead, how well their employer manages 
Table 2 Summary of mediation results

\begin{tabular}{llll}
\hline & Mediator: engagement leadership & Mediator: community engagement & Mediator: degree of formalization \\
\hline Total effect $(c)$ & $0.21^{*}$ & $0.30^{*}$ & $0.19^{*}$ \\
Indirect effect $[(a * b) / \mathrm{SDy}]$ & $0.15^{*}$ & $0.12^{*}$ & $0.16^{*}$ \\
Direct effect & 0.06 & $0.18^{*}$ & 0.02 \\
Proportion mediated $[(a * b) / c]$ & $69 \%$ & $41 \%$ & $87 \%$
\end{tabular}

*Indicates $p<.001$

stakeholder relationships plays a more significant role. Detailed results are discussed below.

The application of the stakeholder theory helped to identify internal and external stakeholders employees may feel responsible for given the social missions nonprofits focus on (van Puyvelde et al., 2012). This study demonstrates that how a nonprofit manages its relationship with internal and external stakeholders would influence its employees' commitment. Consistent with the literature, results showed that employees expect nonprofit executives and board members to be mindful of their agency and to encourage their participation in decision-making (Ohana et al. 2013). Stimulating their involvement through engaged leadership helps create a participatory environment where employees' voices are heard and acted upon, thus reducing the risk of losing their commitment.

Nonprofit employees also expect their organizations to formalize daily operations so there is a clear goal to follow through and a documentation of responsibility. This notion is related to the increasing number of publications about nonprofit's operational capacity (Shumate et al., 2017). Formalized operation ensures consistent internal communication and a supportive culture of innovation and accountability, which influence organizational effectiveness and the achievement of its mission (Maier et al., 2016). The significant effect of formalized operation on organizational commitment thus provides evidence that nonprofits need to establish clear procedures in daily operations and build accountability measures to retain their employees.

Furthermore, given the social mission nonprofits focus on employees also expect the organization to be more actively engaged in the local community it serves. Maintaining communication and outreach effort with local communities may offer altruistic motivations for nonprofit employees to stay in their organizations, as such effort showcases the organization's commitment to stay true to its social mission and to tackle root cause. How external stakeholder engagement may affect organizational commitment had not been directly examined in the nonprofit literature. However, the result was not surprising given the nature of the sector. This finding offers additional evidence about the importance of mission alignment (Akingbola \& van den Berg, 2019). The more the effort nonprofits place in engaging with external stakeholders such as community partners, the more aligned employees view their personal motivation with organizational mission.

Guided by OST, this study also found that intangible support such as professional development and career advancement opportunities mattered while tangible support such as perceived fair pay had no direct effect on organizational commitment. This indicates that nonprofit employees view intangible support as a more relevant aspect of their relationship with their organization. Given that on average the respondents rated relatively low on the perceived fair pay $(M=3.00$, S.D. $=1.47)$, there might be a potential cognitive conflict between how well they are serving a social mission and how stable their financial situation is. Therefore, they would rather place the priority upon the social mission and sacrifice the financial stability. Furthermore, the significant effect of intangible support shows that employees may experience a sense of personal growth and value, which motivates them to stay committed (Salim et al., 2012). One finding worth noting is the importance of mental health support, which is measured as a dimension of intangible support. It provides further evidence that nonprofit employees expect their organizations to understand and care about their psychological well-being (Baluch, 2017).

The post hoc analysis showed that the tangible support's effect on organizational commitment went through stakeholder management variables. It indicates that when nonprofits fulfill expectations from both internal and external stakeholders, the positive relationship between fair pay and organizational commitment will be much more possible. This provides additional evidence that to facilitate workforce stability, nonprofits should establish clear procedures to ensure the effective engagement with their employees and the communities served. Furthermore, it shows that nonprofit employees are not only thinking about extrinsic and instrumental benefits they may receive from the job, but more about how the larger community may benefit. 


\section{Nonprofit Management Implications}

The nuanced effects revealed in this study have important implications for nonprofit management, and in particular for how to improve workforce stability. Nonprofits should establish clear role responsibilities for the board of directors and encourage their engagement and communication with the employees to be informed of their work. Board training or orientation should be implemented to ensure the clarity of the board members' roles and responsibility and to ensure the accountability of their activities or inactivity. The executive management team should adopt a leadership style that listens to employees' voices and acts on employees' recommendations, and avoids micromanaging to provide them agency to achieve their goals. Effective leadership helps to maintain a participatory work environment and retain the employees. The key is to show leadership accountability and to provide enough autonomy to allow the employees to engage in problem solving through their creativity and passion in the social mission.

Another important key takeaway is that nonprofits should have a clear understanding of the root cause of the social issue being tackled and engage with the local community to share their work progress and to build sustainable partnerships. These practices will improve the employees' perceived organizational pride. Thus, fulfilling the social mission through community engagement will bring nonprofits benefits as it helps to enhance the employees' identification with the organization.

Furthermore, nonprofits should establish more formalized organizational structures and management practices to foster the accountability of all the employees. It could include installing the practice of collecting systematic data for performance review, encouraging employees to engage in innovative activities, and effective internal communication to make sure all the tasks are structured clearly to avoid ambiguity. Being more formalized in daily operations helps to align employees toward shared organizational goals and motivate them to be more proactive. This will bring nonprofits numerous benefits, as employees will likely remain as organizational members, identify with the organization's goal and mission, and advocate for the organization.

Last but not least, nonprofits should provide intangible organizational support to enhance employees' organizational commitment, for example being prepared to provide counseling services and other support to employees that suffer from mental health issues, and offer professional development opportunities such as leadership training and project management training.

\section{Limitations and Future Research}

Several limitations of this current research warrant further research. First, data were collected from one city located in a southeast state of the USA. Though the response rate was fairly high and the research team took measures to recruit more diverse participants, the findings should not be easily generalized to other contexts. However, the method and analysis can be replicated to other states and countries to further examine whether the patterns revealed can be validated in other settings.

Second, this current study focused on understanding the antecedents of organizational commitment. Therefore, it did not consider the outcomes of organizational commitment. Several areas are worth further investigation. For example, how does organizational commitment influence employees' perceived organizational identification, job satisfaction, and organizational performance?

Third, measurements used in this study were focused on behavioral intentions or perceptions, instead of actual actions taken. For example, organizational commitment data were collected as behavioral intentions; external stakeholder engagement was measured with employees' perception of how well the organization understands root causes of a social issue, and how well it engages in stakeholder communication and partnership-building. Given that data were self-reported, further research should look into other data sources to examine if the patterns revealed here would still hold significant if the behavioral and observational data were collected.

Last, this study did not measure specific leadership types and their effects. Rather, the focus was on how employees perceived their leaders' engagement with them and their peers, as a proxy to measure to what degree nonprofits encourage employee participation. Findings suggested that a more participatory leadership style could help enhance organizational commitment. Future research should examine and compare the effects of different leadership types (Erdurmazl1, 2019).

\section{Conclusion}

This study demonstrates that nonprofit should effectively engage with both internal and external stakeholders to ensure workforce stability. This could be achieved by having leadership that listens to employees' voices and acts upon their suggestions, building sustainable relationships with community partners, and having more formalized operational procedures. These factors related to stakeholder engagement also significantly mediate the positive relationship between perceived tangible organizational support and organizational commitment, further providing 
evidence about the importance of stakeholder engagement in retraining nonprofit employees. Furthermore, the results highlight the value the employees place on intangible support their organizations may offer as incentives to stay, including professional development and career advance opportunity and care for their mental health needs.

This study makes several important contributions to the literature on nonprofit management and employee engagement. First, it demonstrates the importance of engagement with both internal and external stakeholders in influencing nonprofit employees' organizational commitment. Findings suggest that when employees assess their decisions to stay in a nonprofit, they care about a much larger community context that is beyond themselves. Second, this study highlights important internal and external communication issues nonprofits need to address to improve the workforce stability, which move beyond the traditional communication effort such as fundraising, donor relationships, and social media campaigns (Fischer Liu 2012). In particular, it shows that nonprofits need to invest in more formalized daily operations to ensure professionalism at the work place, and in building sustainable communication with community partners. Furthermore, additional communication effort should be placed upon listening to employees' needs, including their willingness to participate in decision-making, and also their needs in professional development.

The data analyzed in this study were collected prior to the COVID-19 pandemic. A recent survey of 582 nonprofit organizations across the state where the study was conducted reported that $92 \%$ of the respondents experienced disruption in programs and services due to COVID-19 and $51 \%$ downsized, negatively impacting 489,000 citizens (Kentucky Nonprofit Network, 2020b). Future research should investigate how the vulnerabilities (e.g., financial stability, work-life balance) generated by COVID-19 may have impacted the relationships examined in this current study, and what additional factors need to be taken into consideration when evaluating how to ensure nonprofit workforce stability during social disruptions.

Acknowledgements The author would like to thank the CivicLex and Impaktfel teams for their valuable effort in participant recruitment and data collection.

Funding No funding was received to assist with the preparation of this manuscript. The author has no relevant financial or non-financial interests to disclose.

\section{References}

Akingbola, K., \& van den Berg, H. A. (2019). Antecedents, consequences, and context of employee engagement in nonprofit organizations. Review of Public Personnel Administration, 39(1), 46-74.

Alexander L. B. (2017) Why Women are Still Underrepresented in Nonprofit Leadership and What We Can Do About It. Retrieved on October 21st, 2019 from https://www.nonprofithr.com/ women-underrepresented-nonprofit-leadership/

Allen, N. J., \& Meyer, J. P. (1990). The measurement and antecedents of affective, continuance and normative commitment to the organization. Journal of Occupational Psychology, 63(1), 1-18.

Angle, H. L., \& Perry, J. L. (1981). An empirical assessment of organizational commitment and organizational effectiveness. Administrative Science Quarterly, 26(1), 1-14.

Balser, D., \& McClusky, J. (2005). Managing stakeholder relationships and nonprofit organization effectiveness. Nonprofit Management and Leadership, 15(3), 295-315.

Baluch, A. M. (2017). Employee perceptions of HRM and well-being in nonprofit organizations: Unpacking the unintended. The International Journal of Human Resource Management, 28(14), 1912-1937.

Bartlett, K. R. (2001). The relationship between training and organizational commitment: A study in the health care field. Human Resource Development Quarterly, 12(4), 335-352.

Bassous, M. (2015). What are the factors that affect worker motivation in faith-based nonprofit organizations? Voluntas International Journal of Voluntary and Nonprofit Organizations, 26(1), 355-381.

Ben-Ner, A., \& Van Hoomissen, T. (1991). Nonprofit organizations in the mixed economy. Annals of Public and Cooperative Economics, 62(4), 519-550.

Boezeman, E. J., \& Ellemers, N. (2007). Volunteering for charity: Pride, respect, and the commitment of volunteers. Journal of Applied Psychology, 92, 771-785.

Brimhall, K. C. (2019). Inclusion is important but how do i include? Examining the effects of leader engagement on inclusion, innovation, job satisfaction, and perceived quality of care in a diverse nonprofit health care organization. Nonprofit and Voluntary Sector Quarterly, 48(4), 716-737.

Brown, W. A., \& Yoshioka, C. F. (2003). Mission attachment and satisfaction as factors in employee retention. Nonprofit Management and Leadership, 14(1), 5-18.

Dart, R. (2004). Being "business-like" in a nonprofit organization: A grounded and inductive typology. Nonprofit and Voluntary Sector Quarterly, 33(2), 290-310.

Defourny, J., \& Nyssens, M. (2008). Social enterprise in Europe: Recent trends and developments. Social Enterprise Journal, 4, 202-228.

Doherty, A., \& Hoye, R. (2011). Role ambiguity and volunteer board member performance in nonprofit sport organizations. Nonprofit Management and Leadership, 22(1), 107-128.

Eikenberry, A. M. (2009). Refusing the market: A democratic discourse for voluntary and nonprofit organizations. Nonprofit and Voluntary Sector Quarterly, 38(4), 582-596.

Erdurmazlı, E. (2019). Satisfaction and commitment in voluntary organizations: A cultural analysis along with servant leadership. VOLUNTAS: International Journal of Voluntary and Nonprofit Organizations, 30(1), 129-146.

Fisher, L. B. (2012). Toward a better understanding of nonprofit communication management. Journal of Communication Management, 16(4), 388-404.

Hayes, A. F., \& Scharkow, M. (2013). The relative trustworthiness of inferential tests of the indirect effect in statistical mediation analysis: Does method really matter? Psychological Science, 24(10), 1918-1927.

Hodge, M. M., Hodge, M. M., \& Piccolo, R. F. (2011). Nonprofit board effectiveness, private philanthropy, and financial vulnerability. Public Administration Quarterly, 35(4), 520-550. 
Huynh, J. Y., Metzer, J. C., \& Winefield, A. H. (2012). Validation of the four-dimensional connectedness scale in a multisample volunteer study: A distinct construct from work engagement and organisational commitment. VOLUNTAS: International Journal of Voluntary and Nonprofit Organizations, 23(4), 1056-1082.

Jaskyte, K. (2004). Transformational leadership, organizational culture, and innovativeness in nonprofit organizations. Nonprofit Management \& Leadership, 15(2), 153-168.

Jaskyte, K. (2011). Predictors of administrative and technological innovations in nonprofit organizations. Public Administration Review, 71(1), 77-86.

Kania, J., \& Kramer, M. (2011). Collective impact (pp. 36-41). FSG

Kang, C., Huh, S., Cho, S., \& Auh, E. (2015). Turnover and retention in nonprofitemployment: The korean college graduates' experience. Nonprofit and Voluntary Sector Quarterly, 44(4), 641-664.

Kearns, K. P. (2004). Management-capacity building in the Pittsburgh region. Nonprofit Management and Leadership, 14(4), 437-452.

Kentucky Nonprofit Network (2020a). Kentucky nonprofits: More than charity. Retrieved on October 1st 2019 from https://www. kynonprofits.org/advocate/MoreThanCharity

Kentucky Nonprofit Network (2020b). Updated rapid response survey: KY nonprofits \& COVID-19. Retrieved on October 19 2020 from https://www.kynonprofits.org/sites/default/files/ COVID\%20FOLLOW-UP\%20Rapid\%20Response\%20Sur vey\%20Report.pdf

Kim, S. E., \& Lee, J. W. (2007). Is mission attachment an effective management tool for employee retention? An empirical analysis of a nonprofit human services agency. Review of Public Personnel Administration, 27(3), 227-248.

Knapp, J. R., Smith, B. R., \& Sprinkle, T. A. (2017). Is it the job or the support? Examining structural and relational predictors of job satisfaction and turnover intention for nonprofit employees. Nonprofit and Voluntary Sector Quarterly, 46(3), 652-671.

Kurtessis, J. N., Eisenberger, R., Ford, M. T., Buffardi, L. C., Stewart, K. A., \& Adis, C. S. (2017). Perceived organizational support: A meta-analytic evaluation of organizational support theory. Journal of Management.

Lanfranchi, J., \& Narcy, M. (2015). Female overrepresentation in public and nonprofit sector jobs: Evidence from french national survey. Nonprofit and Voluntary Sector Quarterly, 44(1), 47-74.

Lee, C., \& Nowell, B. (2015). A framework for assessing the performance of nonprofit organizations. American Journal of Evaluation, 36(3), 299-319.

Lee, Y. J. (2016). Comparison of job satisfaction between nonprofit and public employees. Nonprofit and Voluntary Sector Quarterly, 45(2), 295-313.

LeRoux, K., \& Feeney, M. K. (2013). Factors attracting individuals to nonprofit management over public and private sector management. Nonprofit Management and Leadership, 24(1), 43-62.

Lewis, L. (2005). The civil society sector: A review of critical issues and research agenda for organizational communication scholars. Management Communication Quarterly, 19(2), 238-267.

Maier, F., Meyer, M., \& Steinbereithner, M. (2016). Nonprofit organizations becoming business-like: A systematic review. Nonprofit and Voluntary Sector Quarterly, 45(1), 64-86.

Meyer, J. P., Allen, N. J., \& Smith, C. A. (1993). Commitment to organizations and occupations: Extension and test of a threecomponent conceptualization. Journal of Applied Psychology, 78(4), 538-551.

Meyer, J. P., \& Parfyonova, N. M. (2010). Normative commitment in the workplace: A theoretical analysis and re-conceptualization. Human Resource Management Review, 20(4), 283-294.
Miller, J. L., \& Faerman, S. R. (2003). Making good board choices: A competing values approach. Nonprofit Quarterly, 10, 48-53.

Ohana, M., Meyer, M., \& Swaton, S. (2013). Decision-making in social enterprises: Exploring the link between employee participation and organizational commitment. Nonprofit and Voluntary Sector Quarterly, 42(6), 1092-1110.

Porter, L. W., Steers, R. M., Mowday, R. T., \& Boulian, P. V. (1974). Organizational commitment, job satisfaction, and turnover among psychiatric technicians. Journal of Applied Psychology, 59(5), 603-609.

Powell, D. M., \& Meyer, J. P. (2004). Side-bet theory and the threecomponent model of organizational commitment. Journal of Vocational Behavior, 65(1), 157-177.

Presti, A. L. (2013). The interactive effects of job resources and motivations to volunteer among a sample of Italian volunteers. VOLUNTAS: International Journal of Voluntary and Nonprofit Organizations, 24(4), 969-985.

Reid, W., \& Turbide, J. (2012). Board/staff relationships in a growth crisis: Implications for nonprofit governance. Nonprofit and Voluntary Sector Quarterly, 41(1), 82-99.

Ridder, H., \& McCandless, A. (2010). Influences on the architecture of human resource management in nonprofit organizations. Nonprofit and Voluntary Sector Quarterly, 39(1), 124-141.

Salamon, L. M., Newhouse, C. L. \& Sokolowski, S.W. (2019). The 2019 nonprofit employment report. Johns Hopkins Center for Civil Society Studies, retrieved on Oct1st 2019 from http://ccss. jhu.edu/wp-content/uploads/downloads/2019/01/2019-NPEmployment-Report_FINAL_1.8.2019.pdf

Salim, L., Sadruddin, S., \& Zakus, D. (2012). Organizational commitment in a health NGO in Pakistan. VOLUNTAS: International Journal of Voluntary and Nonprofit Organizations, 23(3), 584-604.

Sanders, M. L., \& McClellan, J. G. (2014). Being business-like while pursuing a social mission: Acknowledging the inherent tensions in US nonprofit organizing. Organization, 21(1), 68-89.

Shumate, M., Cooper, K. R., Pilny, A., \& Pena-y-lillo, M. (2017). The nonprofit capacities instrument. Nonprofit Management and Leadership, 28(2), 155-174.

Smith, J. M., Arendt, C., Lahman, J. B., Settle, G. N., \& Duff, A. (2006). Framing the work of art: Spirituality and career discourse in the nonprofit arts sector. Communication Studies, 57(1), $25-46$.

Truss, C., Shantz, A., Soane, E., Alfes, K., \& Delbridge, R. (2013). Employee engagement, organisational performance and individual well-being: Exploring the evidence, developing the theory. International Journal of Human Resource Management, 24, 2657-2669.

US Bureau of Statistics (2020). Local area unemployment statistics. Retrieved on September 22, 2020 from https://data.bls.gov/ timeseries/LAUMT213046000000004?amp\%253bdata_tool= XGtable\&output_view=data\&include_graphs=true

Valeau, P., Willems, J., \& Parak, H. (2016). The effect of attitudinal and behavioral commitment on the internal assessment of organizational effectiveness: A multilevel analysis. VOLUNTAS: International Journal of Voluntary and Nonprofit Organizations, 27(6), 2913-2936.

Van Puyvelde, S., Caers, R., Du Bois, C., \& Jegers, M. (2012). The governance of nonprofit organizations: Integrating agency theory with stakeholder and stewardshiptheories. Nonprofit and Voluntary Sector Quarterly, 41(3), 431-451.

Wright, B. E., \& Millesen, J. L. (2008). Nonprofit board role ambiguity: Investigating its prevalence, antecedents, and conse- 
quences. The American Review of Public Administration, 38(3), 322-338.

Yahaya, R., \& Ebrahim, F. (2016). Leadership styles and organizational commitment: Literature review. Journal of Management Development, 35(2), 190-216.

Yousef, D. A. (2017). Organizational commitment, job satisfaction and attitudes toward organizational change: A study in the local government. International Journal of Public Administration, 40(1), 77-88.
Zollo, L., Laudano, M. C., Boccardi, A., \& Ciappei, C. (2019). From governance to organizational effectiveness: the role of organizational identity and volunteers' commitment. Journal of Management and Governance, 23(1), 111-137.

Publisher's Note Springer Nature remains neutral with regard to jurisdictional claims in published maps and institutional affiliations. 